\title{
Studies on the Characteristics of the Control
}

\section{System Governing Sodium Excretion in Uremic Man}

\author{
Eduardo Slatopolsky, Ivan O. Elkan, Carol Weerts, and Neal S. Bricker \\ From the Renal Division, Department of Internal Medicine, Washington \\ University School of Medicine, St. Louis, Missouri
}

A B S T RAC T Sodium excretion was studied in a group of patients with chronic renal disease, (a) on constant salt intakes of varying amounts with and without mineralocorticoid hormone administration and, (b) after acute extracellular fluid volume expansion. The lower the steady-state glomerular filtration rate (GFR), the greater was the fraction of filtered sodium excreted on both a 3.5 and $7.0 \mathrm{~g}$ salt diet; and the lower the GFR, the greater was the change in fractional excretion in the transition from the 3.5 to the $7.0 \mathrm{~g}$ salt diet. This regulatory capacity did not appear to be influenced by mineralocorticoid hormone administration. After acute expansion of extracellular fluid (ECF) volume, the increment in sodium excretion exceeded the concomitant increment in filtered sodium in six of nine studies and in the remaining three studies, the increment in excretion averaged $59 \%$ of the $\Delta$ filtered load (i.e., only $41 \%$ of the increase in filtered sodium was reabsorbed). During saline loading, the decrease in fractional reabsorption of sodium tended to vary inversely with the steady-state GFR, although all patients received approximately the same loading volume. When an edema-forming stimulus was applied during saline infusion, the natriuretic response was aborted and the lag time was relatively short. When GFR and the filtered load of sodium were increased without volume expansion, the $\Delta$ sodium

Dr. Ivan O. Elkan is a Research Associate at the John Cochran Veterans Administration Hospital. Dr. Neal S. Bricker is a recipient of a U. S. Public Health Service Career Research Award.

Received for publication 5 June 1967 and in revised form 1 November 1967. excretion averaged only $19 \%$ of the $\Delta$ filtered load; moreover, changes in fractional sodium reabsorption were considerably smaller than those observed during saline loading. The data implicate the presence of a factor other than GFR and mineralocorticoid changes in the modulation of sodium excretion in uremic man.

\section{INTRODUCTION}

It is unusual for a patient with chronically progressive renal disease either to accumulate edema or to sustain net sodium loss on an average salt intake. If this clinical observation reflects a continuing ability to maintain external sodium balance in the face of a diminishing number of functioning nephrons, sodium excretion/nephron must increase with time. Moreover, if external sodium balance is maintained on an unrestricted salt intake, the range over which sodium excretion varies in single nephrons must increase progressively as the nephron population decreases if ordinary dayto-day variations in salt intake are to be accommodated. Thus, to effect a change in total sodium excretion of any given magnitude, the average change in excretion per nephron must vary inversely with the number of nephrons. If this requirement for exaggerated changes in sodium excretion (per nephron) is fulfilled in chronic renal disease, an unusual opportunity might exist to distinguish tubular from glomerular contributions to the regulation of sodium excretion.

In the present study some aspects of the control of sodium excretion have been studied in uremic patients. 


\section{METHODS}

Studies were performed on 17 patients with chronically progressive renal disease. Eight had chronic glomerulonephritis, six chronic pyelonephritis, and three polycystic renal disease. Glomerular filtration rate (GFR) ranged from 1.2 to $63 \mathrm{ml} / \mathrm{min}$. Studies also were performed on two normal volunteers. All of the subjects were informed of the experimental nature of the studies and each participated willingly. Several different protocols were followed.

Sodium excretion with different levels of salt intake. Patterns of sodium excretion were investigated in eight patients with chronic renal disease and in two normal individuals on the wards of the Clinical Research Center. All of the patients subsisted on both a $3.5 \mathrm{~g}$ and a $7.0 \mathrm{~g}$ salt diet; in selected studies, $250 \mathrm{mg}$ and $10 \mathrm{~g}$ salt diets also were employed. Each diet was maintained for a minimum of 5 days and sodium intake was regulated in the following manner. The basic daily diet contained $2 \mathrm{~g}$ of $\mathrm{NaCl}$. To this diet, each subject added a weighed quantity of $\mathrm{NaCl}$ calculated to bring the 24-hr intake to the desired level. The patients were instructed to use all of the salt and to eat all of the food to which salt was added. Any nonsalted food left was weighed and corrections were made in computing the sodium intake. When the deviations were appreciable, the dietitian, who supervised the patients closely, encouraged them to ingest an additional amount of salt sufficient to bring the total intake to the prescribed level.

Observations were made with and without chronic administration of $0.2 \mathrm{mg}$ of 9-alpha-fluorohydrocortisone daily. When this drug was administered, it was begun at least 5 days before initial measurements were made. Sodium excretion was determined on 24 -hr urine collections at least twice during each dietary regimen and the values were averaged for the balance computations. Clearance studies were performed after a given salt intake had been in effect for a minimum of 4 days. The priming and sustaining solutions used in the clearance studies contained no $\mathrm{NaCl}$ and the sustaining solution was delivered at a rate of $2 \mathrm{ml} / \mathrm{min}$ to avoid expansion of extracellular fluid volume.

Acute expansion of extracellular fluid volume. Studies on the effects of ECF volume expansion were performed with a hypotonic solution containing $90 \mathrm{~mm} \mathrm{NaCl}$ and 60 $\mathrm{mm}$ glucose, $0.2 \mathrm{mg}$ of 9-alpha-fluorohydrocortisone, $10 \mathrm{mg}$ of desoxycorticosterone acetate (DOCA), and $3 \mathrm{U}$ of pitressin tannate in oil were administered routinely in the morning before beginning the infusion. In each patient, three or more control clearance periods were obtained. Thereafter ECF volume was expanded. 11/2-2 liters of hypotonic saline were infused over an interval of approximately $2 \mathrm{hr}$ and a sustaining solution of the same composition was continued at a rate of $6-8 \mathrm{ml} / \mathrm{min}$ throughout the remainder of the study. At least three experimental clearance periods were obtained after volume expansion had been effected. In several patients, after completion of the latter periods, the saline infusion was continued and an edema-forming stimulus was induced. This consisted of the application of tourniquets to both thighs at subdiastolic pressures (1). After an equilibration period of 20-30 min, two additional clearance periods were obtained with the cuffs inflated.

Increase in GFR without volume expansion. We have found that the administration of bovine parathyroid hormone (PTH) increases GFR in most uremic patients. To examine the effects of an increase in GFR without volume expansion, the patterns of sodium excretion were studied after the intravenous administration of $250 \mathrm{U}$ of PTH as a priming dose and the infusion of $1 \mathrm{U} / \mathrm{min}$ of PTH. Three control periods were obtained before PTH administration and three or more clearance periods were collected during the infusion of PTH.

The clearance of inulin was used to measure GFR. Corrections were made for inuloid blank in the plasma (as a concentration term) and for the excretion of inuloid blank in the urine (as an excretion rate term). The duration of individual clearance periods ranged from 12 to 40 min, depending upon the rate of urine flow. Indwelling catheters were employed for the volume expansion and $\mathrm{PTH}$ infusion studies, and rigorous aseptic technique was maintained in the manner described previously (2). No patients developed a urinary tract infection. (Urine cultures were obtained routinely at the end of these studies and on at least two occasions subsequent to the day of study.) When a catheter was used, each urine collection period was concluded with at least two bladder rinses with distilled water and one or more rinses with air. When voided urines were collected, the collection periods were prolonged and the patients either sat or stood during the brief interval of time required to collect the urine. Blood was collected at the midpoint of each clearance period by an indwelling venous catheter. Creatinine and urea clearances were performed on the same samples of plasma and urine used for inulin determinations. The mean value of creatinine plus urea clearances closely approximated the concurrent values for inulin clearance, thus serving as a check on the validity of the inulin clearance values (3).

Inulin was determined according to the method of Roe, Epstein, and Goldstein (4) and plasma and urine sodium concentrations were measured on a flame photometer (Instrumentation Laboratory Inc., Watertown, Mass.).

\section{RESULTS}

The results of sodium balance studies on eight patients maintained on both a 3.5 and $7.0 \mathrm{~g}$ salt diet are shown in Fig. 1. GFR for the group ranged from a maximum of $25 \mathrm{ml} / \mathrm{min}$ to a minimum of $2.6 \mathrm{ml} / \mathrm{min}$. In each of these patients, external sodium balance was maintained on both levels of salt intake with reasonable accuracy.

The relationship between the fraction of filtered sodium excreted and the GFR over a range of GFRs from 2 to $120 \mathrm{ml} / \mathrm{min}$ is shown in Fig. 2 . In the insert, two theoretical curves are presented 


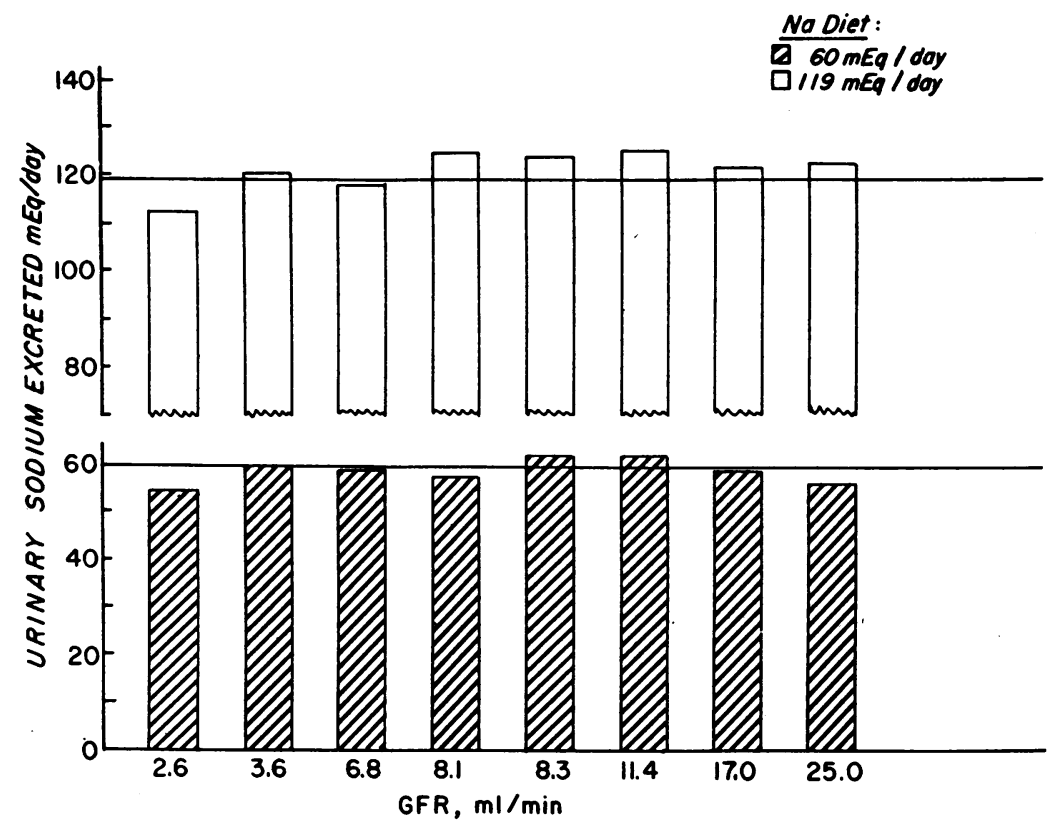

FIGURE 1 Sodium balance studies on 3.5 and $7.0 \mathrm{~g}$ salt diets. The horizontal lines represent sodium intake. The height of the vertical bars represents the mean of at least 2 24-hr sodium excretion rates. GFR, glomerular filtration rate.

to depict the patterns of sodium excretion that are required for the maintenance of external sodium balance on a constant intake of 3.5 and $7.0 \mathrm{~g}$ of salt, respectively, as the nephron population (and GFR) diminishes. The lower the GFR, the greater must be the fraction of sodium excreted. With both levels of salt intake, the rela- tionship is such that for every $50 \%$ reduction in GFR, fractional excretion increases twofold. Moreover, at any given GFR, the lower the value for GFR the greater is the change in fractional sodium excretion associated with the increase in salt intake from 3.5 to $7.0 \mathrm{~g} /$ day. The experimental points derived in the present studies are shown in

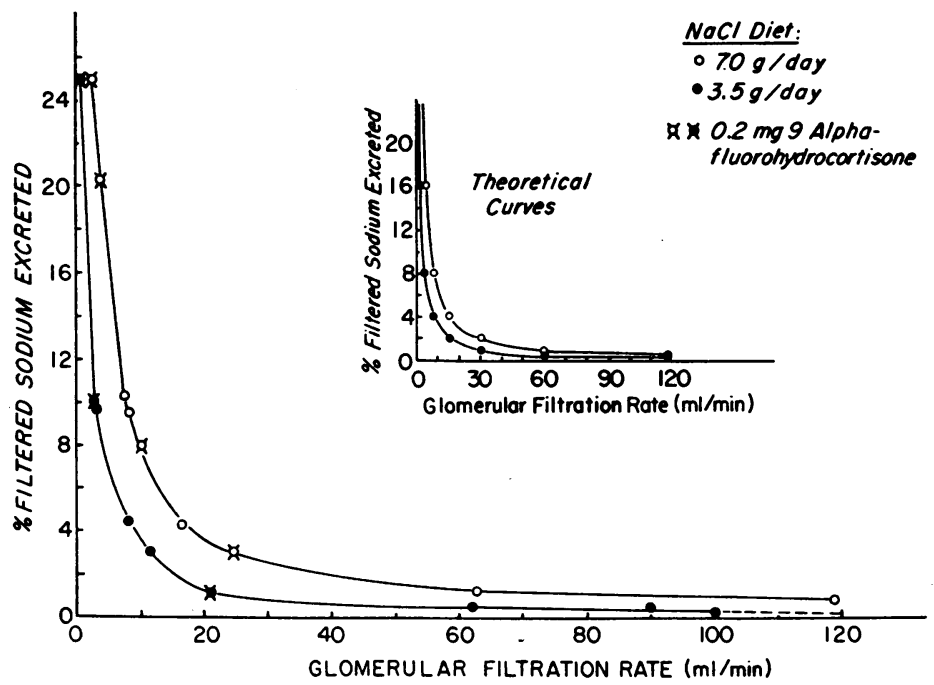

FIGURE 2 The relationship between steadystate GFR and the fraction of filtered sodium excreted on 3.5 and $7.0 \mathrm{~g}$ salt diets. 


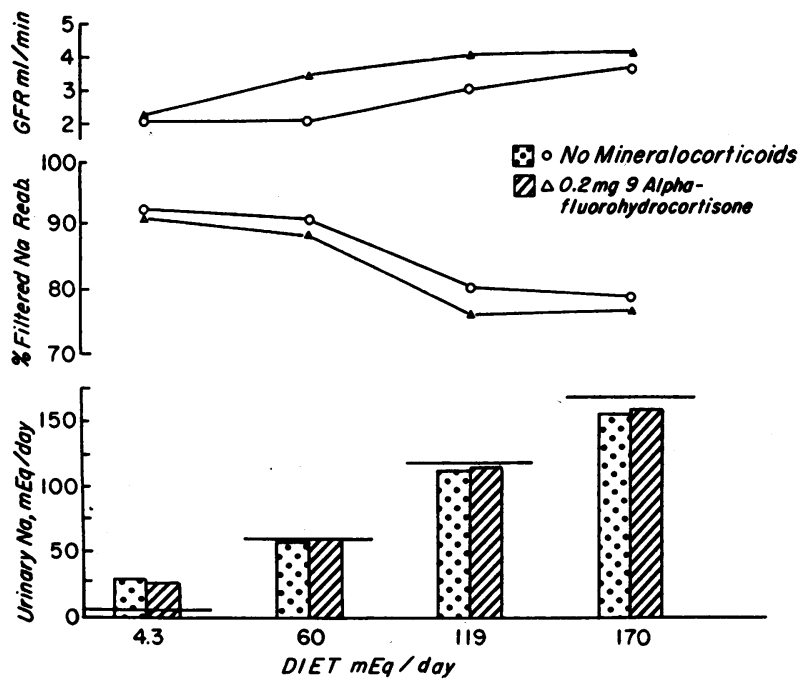

FIGURE 3 GFR, fractional sodium reabsorption, and external sodium balance with and without fluorohydrocortisone on varying salt intakes. The upper part of Fig. 3 represents data from clearance studies, the lower part balance measurements.

the two principal curves in Fig. 2. On both the $3.5 \mathrm{~g}$ and the $7.0 \mathrm{~g}$ salt diet, the curves transcribed closely resemble the theoretical ones. In approximately half of these studies, fluorohydrocortisone was administered daily; in the rest, no exogenous mineralocorticoid hormone was given. No difference is discernible between the two populations.

A more detailed examination of the influence of fluorohydrocortisone on sodium excretion in a patient with a markedly reduced GFR is shown

TABLE I

Effects of Extracellular Fluid Volume Expansion on the Filtered Load of Sodium and Sodium Excretion

\begin{tabular}{|c|c|c|c|c|c|c|c|c|c|c|c|}
\hline Experiment & GFR & $\Delta \mathrm{GFR}$ & $\mathrm{FL}^{*}$ & $\mathrm{UNa}_{\mathrm{Na}}$ & $\mathrm{V}$ & $\mathrm{UNa}_{\mathrm{Na}} \mathrm{V}$ & $\Delta \mathrm{FL}$ & $\Delta \mathrm{U}_{\mathrm{NaV}}$ & $\frac{\Delta \mathrm{UNaV}_{\mathrm{Na}}}{\Delta \mathrm{FL}}$ & $\begin{array}{l}\text { Frac- } \\
\text { tional } \\
\text { reab- } \\
\text { sorption§̧ }\end{array}$ & $\begin{array}{l}\Delta \text { Frac- } \\
\text { tional } \\
\text { reab- } \\
\text { sorption }\end{array}$ \\
\hline & $m l / m i n$ & $\%$ & $\mu E q / \min$ & $\mu E q / m l$ & $m l / m i n$ & $\mu E q / \min$ & $\mu E q / n i m$ & $\mu E q / \min$ & $\%$ & $\%$ & \\
\hline 1 Control & 25.9 & & 3438 & 71.7 & 1.79 & 127 & & & & 96.4 & \\
\hline Expansion & 24.3 & -6.18 & 3027 & 39.1 & 4.46 & 178 & -411 & +51 & & 94.1 & -2.3 \\
\hline \multirow{2}{*}{$\begin{array}{l}2 \text { Control } \\
\text { Expansion }\end{array}$} & 11.4 & & 1500 & 62 & 2.03 & 124 & & & & 91.7 & \\
\hline & 9.47 & -16.9 & 1222 & 50.5 & 2.41 & 128 & -278 & +4 & & 89.5 & -2.2 \\
\hline \multirow{2}{*}{$\begin{array}{l}3 \text { Control } \\
\text { Expansion }\end{array}$} & 7.11 & & 925 & 55.8 & 2.37 & 132 & & & & 85.7 & \\
\hline & 7.36 & +3.52 & 928 & 49.0 & 3.38 & 190 & +3 & +58 & & 79.5 & -6.2 \\
\hline \multirow{2}{*}{$\begin{array}{l}4 \text { Control } \\
\text { Expansion }\end{array}$} & 4.15 & & 536 & 78.6 & 1.52 & 119 & & & & 77.8 & \\
\hline & 3.36 & -19.0 & 417 & 60.9 & 2.53 & 153 & -119 & +34 & & 63.3 & -14.5 \\
\hline \multirow{2}{*}{$\begin{array}{l}5 \text { Control } \\
\text { Expansion }\end{array}$} & 3.35 & & 423 & 72.2 & 1.47 & 117 & & & & 72.5 & \\
\hline & 3.64 & +8.66 & 442 & 77.1 & 2.13 & 164 & +19 & +47 & 247 & 62.9 & -9.6 \\
\hline \multirow{2}{*}{$\begin{array}{l}6 \text { Control } \\
\text { Expansion }\end{array}$} & 2.60 & & 322 & 30.6 & 0.86 & 26.4 & & & & 91.8 & \\
\hline & 2.97 & +14.2 & 347 & 40.8 & 1.98 & 79.8 & +25 & +53.4 & 214 & 77.0 & -14.8 \\
\hline \multirow{2}{*}{$\begin{array}{l}7 \text { Control } \\
\text { Expansion }\end{array}$} & 3.85 & & 510 & 54.2 & 1.06 & 57.7 & & & & 88.7 & \\
\hline & 5.04 & +30.9 & 634 & 53.1 & 2.47 & 131 & +124 & +73.3 & 59.1 & 79.3 & -9.4 \\
\hline \multirow{2}{*}{$\begin{array}{l}8 \text { Control } \\
\text { Expansion }\end{array}$} & 3.16 & & 380 & 48 & 1.61 & 72.2 & & & & 81.0 & \\
\hline & 4.59 & +47.2 & 535 & 59.1 & 2.54 & 150 & +155 & +77.8 & 50.2 & 72.0 & -9.0 \\
\hline \multirow{2}{*}{$\begin{array}{l}9 \text { Control } \\
\text { Expansion }\end{array}$} & 2.90 & & 355 & 49.7 & 1.69 & 82.5 & & & & 77.0 & \\
\hline & 4.82 & +66.0 & 543 & 63.4 & 3.29 & 211 & +188 & +128 & 68.3 & 61.1 & -15.9 \\
\hline
\end{tabular}

* FL, filtered load of sodium (a Donnan factor of 0.95 was used in these calculations).

$\ddagger \mathrm{UNaV}$, sodium excretion rate.

$\S$ Fractional reabsorption, the fraction of filtered sodium reabsorbed. 
TABLE II

Effects of Increasing GFR (Secondary to PTH Administration) on the Filtered Load of Sodium and Sodium Excretion

\begin{tabular}{|c|c|c|c|c|c|c|c|c|c|c|c|}
\hline Patient & GFR & $\Delta \mathrm{GFR}$ & FL & $\mathrm{U}_{\mathrm{Na}}$ & V & $\mathrm{UNa}_{\mathrm{Na}}$ & $\Delta \mathrm{FL}$ & $\Delta \mathrm{U}_{\mathrm{NaV}}$ & $\frac{\Delta \mathrm{UNaV}_{\mathrm{Na}}}{\Delta \mathrm{FL}}$ & $\begin{array}{l}\text { Frac- } \\
\text { tional } \\
\text { reab- } \\
\text { sorption }\end{array}$ & $\begin{array}{c}\Delta F \text { rac- } \\
\text { tional } \\
\text { reab- } \\
\text { sorption }\end{array}$ \\
\hline & $m l / m i n$ & $\%$ & $\mu E q / \min$ & & & $\mu E q / \min$ & $\mu E_{q} / \min$ & $\mu E q / \min$ & $\%$ & $\%$ & \\
\hline 1 a Cont.* & 3.21 & & 444 & 72 & 1.15 & 84.2 & & & & 81.1 & \\
\hline PTH & 3.76 & 17.1 & 514 & 64 & 1.61 & 103 & +70 & +18.8 & 26.9 & 80.0 & -1.1 \\
\hline b Cont. & 3.05 & & 319 & 77.4 & 1.28 & 85.8 & & & & 78 & \\
\hline РTH & 3.49 & 14.4 & 439 & 68.8 & 1.49 & 101 & +48 & +15.2 & 31.7 & 77.1 & -0.9 \\
\hline c Cont. & 3.47 & & 492 & 73.3 & 1.34 & 98.5 & & & & 80.0 & \\
\hline PTH & 4.57 & 31.7 & 645 & 73.7 & 2.19 & 160.6 & +153 & +62.1 & 40.6 & 75.0 & -5.0 \\
\hline 2 a Cont. & 16.7 & & 2139 & 47.9 & 1.91 & 89.4 & & & & 95.8 & \\
\hline PTH & 19.1 & 14.4 & 2406 & 43.9 & 3.84 & 168.8 & +267 & +79.4 & 29.7 & 93.0 & -2.8 \\
\hline b Cont. & 14.4 & & 1861 & 38.3 & 1.90 & 72.1 & & & & 96.0 & \\
\hline PTH & 16.0 & 10.4 & 2024 & 39.8 & 2.93 & 117.4 & +163 & +45.3 & 27.8 & 94.2 & -1.8 \\
\hline c Cont. & 13.6 & & 1728 & 57.3 & 3.04 & 173.8 & & & & 89.9 & \\
\hline PTH & 16.5 & 21.3 & 2045 & 44.1 & 4.40 & 195.9 & +317 & +22.1 & 7.0 & 90.5 & +0.6 \\
\hline 3 a Cont. & 3.02 & & 399 & 65.5 & 1.80 & 118 & & & & 70.4 & \\
\hline PTH & 3.38 & 11.9 & 455 & 68.5 & 2.05 & 142 & +56 & +24 & 42.9 & 68.7 & -1.7 \\
\hline b Cont. & 2.87 & & 375 & 85.5 & 1.50 & 125 & $\cdot$ & & & 66.7 & \\
\hline РTH & 3.38 & 17.8 & 441 & 83.0 & 1.63 & 147 & +66 & +22 & 33.3 & 66.5 & -0.2 \\
\hline c Cont. & 2.48 & & 328 & 42.1 & 0.88 & 30.7 & & & & 90.6 & \\
\hline РTH & 2.95 & 19.0 & 390 & 43.8 & 0.96 & 35.0 & +62 & +4.3 & 6.9 & 91.0 & +0.4 \\
\hline d Cont. & 2.33 & & 310 & 42.3 & 0.73 & 30.8 & & & & 90.0 & \\
\hline РTH & 2.86 & 22.7 & 378 & 43.9 & 0.96 & 34.9 & +68 & +4.1 & 6.0 & 90.8 & +0.8 \\
\hline 4 a Cont. & 12.0 & & 1608 & 26.9 & 4.02 & 108 & & & & 93.3 & \\
\hline РTH & 13.7 & 14.2 & 1816 & 28.8 & 4.66 & 134 & +208 & +26 & 12.5 & 92.6 & -0.7 \\
\hline b Cont. & 9.69 & & 1191 & 46.8 & 3.46 & 162 & & & & 86.4 & \\
\hline PTH & 11.6 & 19.4 & 1425 & 31.7 & 3.62 & 115 & +234 & -47 & -20.1 & 91.9 & +5.4 \\
\hline c Cont. & 8.27 & & 1017 & 39.3 & 2.68 & 105 & & & & 89.7 & \\
\hline РTH & 10.4 & 25.8 & 1256 & 35.0 & 4.04 & 141 & +239 & +36 & 15.1 & 88.8 & -0.9 \\
\hline 5 a Cont. & 6.32 & & 818 & 52.6 & 1.99 & 105 & & & & 87.2 & : \\
\hline PTH & 7.95 & 25.7 & 1026 & 71.6 & 1.97 & 141 & +208 & +36 & 17.3 & 86.2 & -1.0 \\
\hline b Cont. & 5.49 & & 754 & 52.2 & 2.11 & 99.6 & & & & 86.8 & \\
\hline PTH & 6.55 & 19.3 & 820 & 62.2 & 2.10 & 109 & +66 & +9.4 & 14.2 & 86.4 & -0.1 \\
\hline Cont. & 7.91 & & 1025 & 73.5 & 1.88 & 141 & & & & 86.3 & \\
\hline PTH & 8.72 & 10.2 & 1113 & 74.2 & 2.03 & 151 & +88 & +10 & 11.4 & 86.5 & +0.2 \\
\hline Cont. & 3.30 & & 410 & 57.5 & 1.70 & 97.9 & & & & 76.1 & \\
\hline PTH & 3.93 & 19.1 & 483 & 45.9 & 2.29 & 105 & +73 & +7.1 & 9.7 & 78.3 & +2.2 \\
\hline 8 Cont. & 5.11 & & 651 & 51.9 & 3.10 & 162 & & & & 75.3 & \\
\hline PTH & 7.81 & 53.0 & 997 & 56.7 & 4.77 & 269 & +346 & +107 & 31.0 & 73.0 & -2.3 \\
\hline Mean & & 20.4 & & & & & +152 & +26.8 & 19.1 & & -0.54 \\
\hline
\end{tabular}

* Cont., control periods; $\ddagger$ PTH, administration of parathyroid hormone; a, b, c, and d refer to separate studies in the same patient. In Patient 3 the first two studies were performed on a higher daily salt intake than the last two, thus the differences in control fractional reabsorption. 
in Fig. 3. Studies were performed on four levels of salt intake $(250 \mathrm{mg}, 3.5 \mathrm{~g}, 7.0 \mathrm{~g}$, and $10 \mathrm{~g}$ per day) with and without fluorohydrocortisone administration. Sodium balance was maintained both with and without mineralocorticoid administration on the 3.5 and $7.0 \mathrm{~g}$ salt diets. On the 250 $\mathrm{mg}$ salt diet, negative sodium balance ensued, and on the $10 \mathrm{~g}$ salt diet slight positive sodium balance ensued; but fluorohydrocortisone did not appear to influence the regulatory capacity. In clearance studies, GFR tended to be somewhat higher with fluorohydrocortisone and, thus, fractional sodium reabsorption was somewhat lower.

The effects of acute expansion of ECF volume in nine patients are shown in Table I. Fractional sodium reabsorption decreased in all nine patients, ranging from $-2.2 \%$ to $-15.9 \%$. The mean decrement for the group was $-9.3 \%$. In general, the lower the steady-state GFR, the greater the decrease in fractional sodium reabsorption. GFR increased in six of the nine patients and decreased in three. In six of the studies, including the three patients in which GFR decreased, the increment in sodium excretion rate was quantitatively greater than the contemporaneous change in the filtered load of sodium. Sodium excretion rate increased in five of the six patients and remained essentially unchanged in one; but in the latter patient, filtered sodium decreased. In the three studies in which the increase in filtered load exceeded the increase in sodium excretion rate, the increment in excretion varied from 50.2 to $68.3 \%$ of the concurrent increment in filtered sodium. Fractional sodium reabsorption decreased substantially in each of these three patients.

The effects of increasing GFR without expanding ECF volume (i.e., by parathyroid hormone infusion) are depicted in Table II. 18 experiments were performed on 8 patients. In each study, GFR increased; for the group the range was from 10.2 to $53 \%$ with a mean of $20.4 \%$. In contrast to the pattern presented in Table I, fractional sodium reabsorption changed very little in most studies; the changes also occurred in both directions. The mean change for the entire group was $-0.54 \%$ and the range was -5.0 to $+5.4 \%$. The filtered load of sodium increased uniformly, and in each study the increment exceeded the concurrent in-

TABLE III

Effects of Extracellular Volume Expansion before and after PTH Infusion on Sodium Excretion

\begin{tabular}{|c|c|c|c|c|c|c|c|c|c|c|c|}
\hline \multirow[b]{2}{*}{ Period } & \multirow[b]{2}{*}{ Time } & \multirow[b]{2}{*}{ GFR } & \multirow[b]{2}{*}{$\Delta \mathrm{GFR}$} & \multirow[b]{2}{*}{. $\quad \mathrm{V}$} & \multirow[b]{2}{*}{$\mathrm{UNa}_{\mathrm{Na}}$} & \multirow[b]{2}{*}{ FL } & \multirow[b]{2}{*}{$\Delta \mathrm{FL}$} & \multirow[b]{2}{*}{$\mathrm{U}_{\mathrm{Na}} \mathrm{V}$} & \multirow[b]{2}{*}{$\Delta \mathrm{UNa}_{\mathrm{Na}} \mathrm{V}$} & \multirow{2}{*}{$\frac{\Delta \mathrm{U}_{\mathrm{Na}} \mathrm{V}}{\Delta \mathrm{FL}}$} & \multirow{2}{*}{$\begin{array}{c}\text { Frac- } \\
\text { tional } \\
\text { reab- } \\
\text { sorption }\end{array}$} \\
\hline & & & & & & & & & & & \\
\hline & $\min$ & $m l / m i n$ & $\%$ & $m l / m i n$ & $\mu E q / m l$ & $\mu E q / \min$ & $\mu E q / \min$ & $\mu E q / \min$ & $\mu E q / \min$ & $\%$ & $\%$ \\
\hline
\end{tabular}

Inulin prime and sustain started at $-84 \mathrm{~min}$.

$\begin{array}{crrrrrrr}1 & 0-22 & 3.42 & 1.76 & 70.5 & 439 & 124 & 71.8 \\ 2 & 22-38 & 3.49 & 1.56 & 75.2 & 438 & 117 & 73.3 \\ 3 & 38-50 & 3.13 & 1.54 & 70.8 & 393 & 109 & 72.3 \\ \text { Mean } & & 3.35 & 1.61 & & 423 & 117 & 72.5\end{array}$

$2000 \mathrm{ml}$ hypotonic saline infused from 51 to $202 \mathrm{~min}$. Sustaining infusion delivered at $8 \mathrm{ml} / \mathrm{min}$.

\begin{tabular}{|c|c|c|c|c|c|c|c|c|c|c|c|}
\hline 4 & $202-222$ & 3.57 & & 2.04 & 76.0 & 438 & & 155 & & & 64.6 \\
\hline 5 & $222-239$ & 3.74 & & 2.21 & 75.1 & 458 & & 166 & & & 63.8 \\
\hline 6 & $239-255$ & 3.61 & & 2.13 & 80.2 & 429 & & 170 & & & 60.4 \\
\hline Mean & & 3.64 & +8.7 & 2.13 & 77.1 & 442 & +19 & 164 & +47 & 247 & 62.9 \\
\hline
\end{tabular}

$250 \mathrm{U}$ PTH infused as a priming dose. $1 \mathrm{U} / \mathrm{min}$ delivered with hypotonic saline sustaining solution.

\begin{tabular}{|c|c|c|c|c|c|c|c|c|c|c|c|}
\hline 7 & $303-318$ & 4.66 & & 2.87 & 80.1 & 571 & & 230 & & & 59.7 \\
\hline 8 & $318-343$ & 4.33 & & 2.95 & 69.7 & 535 & & 205 & & & 61.7 \\
\hline 9 & $343-362$ & 4.37 & & 2.71 & 76.4 & 558 & & 207 & & & 62.9 \\
\hline Mean & & 4.45 & +22.2 & 2.84 & 75.4 & 555 & +113 & 214 & +50 & 44.2 & 61.4 \\
\hline
\end{tabular}

526 E. Slatopolsky, I. O. Elkan, C. Weerts, and N. S. Bricker 

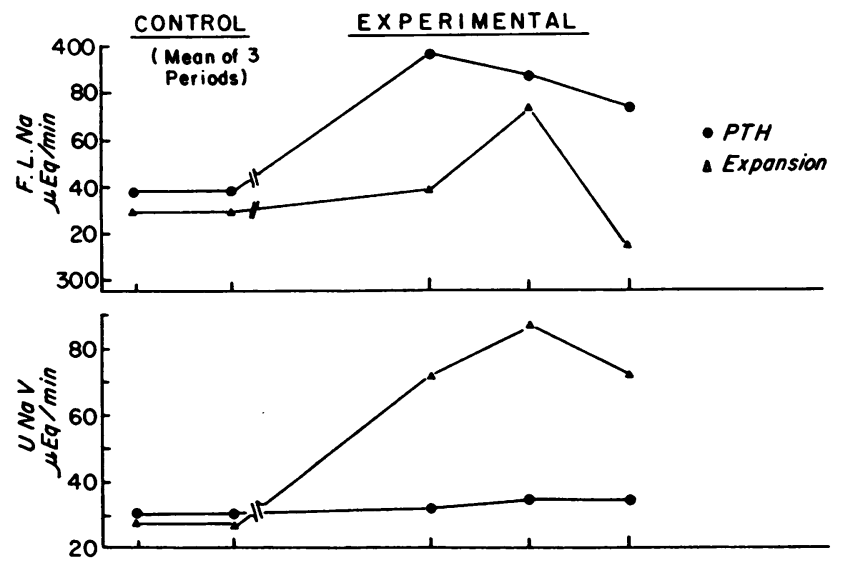

FIGURE 4 The comparative effects on the patterns of sodium excretion of extracellular fluid (ECF) volume expansion vs. an increase in GFR without volume expansion induced by parathyroid hormone administration. In the expansion study, urinary sodium concentrations averaged $30.6 \mathrm{mEq} /$ liter during control periods and $40.8 \mathrm{mEq} /$ liter during expansion. In the PTH study, the control and experimental values were 42.3 and $43.9 \mathrm{mEq} /$ liter, respectively. Urinary volumes averaged 0.86 and $1.98 \mathrm{ml} / \mathrm{min}$ during control and expansion periods and 0.73 vs. $0.96 \mathrm{ml} / \mathrm{min}$ in control and $\mathrm{PTH}$ infusion periods, respectively.

crease in sodium excretion by a substantial degree. In one study, sodium excretion rate decreased; in the remaining 17 studies, it increased. The over-all increase in excretion averaged only $19.1 \%$ of the concurrent increase in filtered load with a range of -20.1 to $+42.9 \%$. Thus there was no overlap in values for $\Delta U_{\mathrm{Na}} \mathrm{V} / \Delta \mathrm{FL}$ between the present studies and those presented in Table I.

Table III shows in detail the effects of superimposing an increase in GFR on preexisting ECF volume expansion. After three control periods, three clearance periods were obtained during volume expansion; then parathyroid hormone was administered while the rate of the sustaining solution used to maintain ECF expansion was maintained constant. ECF expansion was associated with an $8.7 \%$ increase in GFR and a decrease in fractional sodium reabsorption from 72.5 to $62.9 \%$. The increase in sodium excretion rate was $247 \%$ of the increase in filtered sodium. Subsequent to the administration of PTH, GFR increased by $22.2 \%$ from the level achieved during the preceding expansion periods. Despite this change in GFR and filtered sodium, fractional sodium reabsorption decreased only from 62.9 to $61.4 \%$ and the increment in sodium excretion rate averaged $44.2 \%$ of the concurrent increment in filtered sodium.

Fig. 4 presents a comparison of the effects of increasing GFR by hypotonic expansion and by PTH infusion in separate studies on the same patient. The increase in filtered sodium was greater with $\mathrm{PTH}$ than with expansion; yet sodium excretion rate increased by over threefold during ECF expansion, whereas almost no change was observed in the absence of volume expansion. Finally, fractional reabsorption of sodium decreased from 91.8 to $77 \%$ with hypotonic expansion; but it did not change during PTH infusion. Similar results were obtained in two other patients in whom both experiments were performed.

Detailed protocols are presented in Table IV for two patients in whom blood pressure cuffs were inflated about both thighs at the conclusion of the third clearance period in the volume-expanded state. Before inflation of the cuffs in both patients, the increment in sodium excretion rate induced by the saline infusion could not be accounted for quantitatively by the change in filtered load. After inflation of the cuffs to pressures slightly under diastolic blood pressure, and with the continuation of hypotonic saline infusion, the effects of volume expansion were reversed in direction. Thus, in comparison with the values obtained during the expansion periods sodium excretion rate decreased, the change in the filtered load of sodium did not parallel the change in excretion, and fractional sodium reabsorption increased. 
TABLE IV

Effects of Extracellular Fluid Volume Expansion and the Influence of a Superimposed Edema-Forming Stimulus on Sodium Excretion in Uremic Patients

\begin{tabular}{|c|c|c|c|c|c|c|c|c|c|}
\hline Patient & Period & Time & GFR & F.F. & С & $\mathrm{v}$ & FL & $\mathrm{UNaV}_{\mathrm{Na}}$ & $\begin{array}{l}\text { Frac- } \\
\text { tional } \\
\text { reab- } \\
\text { sorption }\end{array}$ \\
\hline \multicolumn{10}{|c|}{ A } \\
\hline \multicolumn{10}{|c|}{ Inulin prime and sustain $(2 \mathrm{ml} / \mathrm{min})$ started at $-52 \mathrm{~min}$. } \\
\hline & 1 & $0-12$ & 23.8 & 0.25 & 96.2 & 1.43 & 3151 & 117 & 96.3 \\
\hline & 2 & $12-26$ & 27.9 & 0.25 & 109.6 & 2.07 & 3722 & 135 & 96.4 \\
\hline & 3 & $26-43$ & 25.9 & 0.26 & 98.4 & 1.87 & 3442 & 125 & 96.4 \\
\hline & Mean & & 25.9 & 0.25 & 100.4 & 1.79 & 3438 & 127 & 96.4 \\
\hline \multicolumn{10}{|c|}{$2000 \mathrm{ml}$ of hypotonic saline infused from 44 to $141 \mathrm{~min}$. Sustaining infusion delivered at $8 \mathrm{ml} / \mathrm{min}$. } \\
\hline & 4 & 141-159 & 22.6 & 0.28 & 80.4 & 4.06 & 2893 & 174 & 94.0 \\
\hline & 5 & $159-172$ & 24.4 & 0.27 & 91.0 & 4.73 & 3040 & 173 & 94.3 \\
\hline & 6 & $172-189$ & 24.9 & 0.26 & 95.1 & 4.88 & 3147 & 185 & 94.1 \\
\hline & Mean & & 24.3 & 0.27 & 88.8 & 4.46 & 3027 & 178 & 94.1 \\
\hline \multicolumn{10}{|c|}{ Inflation of blood pressure cuffs about thighs at subdiastolic pressures at $190 \mathrm{~min}$. } \\
\hline & 7 & $220-236$ & 21.1 & 0.26 & 82.1 & 4.81 & 2680 & 134 & 95.0 \\
\hline & 8 & $236-258$ & 25.5 & 0.29 & 89.0 & 4.09 & 3198 & 143 & 95.5 \\
\hline \multicolumn{10}{|l|}{ B } \\
\hline \multicolumn{10}{|c|}{ Inulin prime and sustain $(2 \mathrm{ml} / \mathrm{min})$ started at $-98 \mathrm{~min}$. } \\
\hline & 1 & $0-34$ & 2.66 & 0.22 & 11.9 & 0.91 & 329 & 28.8 & 91.2 \\
\hline & 2 & $34-64$ & 2.69 & 0.22 & 11.9 & 0.89 & 335 & 26.4 & 92.1 \\
\hline & 3 & $64-83$ & 2.45 & 0.22 & 10.8 & 0.79 & 303 & 23.9 & 92.1 \\
\hline & Mean & & 2.60 & 0.22 & 11.5 & 0.86 & 322 & 26.4 & 91.8 \\
\hline \multicolumn{10}{|c|}{$1500 \mathrm{ml}$ hypotonic saline infused from 84 to $179 \mathrm{~min}$. Sustaining infusion delivered at $6 \mathrm{ml} / \mathrm{min}$. } \\
\hline & 4 & $179-191$ & 2.91 & 0.26 & 11.1 & 1.67 & 340 & 75.6 & 77.8 \\
\hline & 5 & $191-203$ & 3.31 & 0.25 & 13.4 & 2.13 & 387 & 91.0 & 76.5 \\
\hline & 6 & $203-215$ & 2.68 & 0.25 & 10.6 & 2.13 & 313 & 72.8 & 76.7 \\
\hline & Mean & & 2.97 & 0.25 & 11.7 & 1.98 & 347 & 79.8 & 77.0 \\
\hline \multicolumn{10}{|c|}{ Inflation of blood pressure cuffs about thighs at subdiastolic pressures at $216 \mathrm{~min}$. } \\
\hline & 7 & , 236-256 & 3.20 & 0.24 & 13.6 & 1.49 & 367 & 57.2 & 84.4 \\
\hline & 8 & $256-276$ & 2.55 & 0.22 & 11.7 & 1.20 & 298 & 37.4 & 87.4 \\
\hline
\end{tabular}

\section{DISCUSSION}

The kidney must make essentially the same contribution to the preservation of sodium balance in chronic renal disease as in health. Thus, excretion must be correlated with the intake of sodium, rather than with the number of functioning nephrons. This requires a continuing change in the excretory profile of individual nephrons as their numbers diminish. If salt appetite and intake do not change substantially as the underlying dis- ease advances, excretion of sodium/nephron must increase as the nephron population diminishes.

In the present study, some aspects of sodium excretion have been examined in patients with chronic renal disease. On two different levels of salt intake ( 3.5 and $7.0 \mathrm{~g}$ /day), external sodium balance was maintained in a group of patients encompassing a wide range of GFRs and, presumably, an equally wide range of severity of underlying disease. In accordance with theoretical 
requirements for external balance, for every $50 \%$ reduction in steady-state GFR, the fraction of filtered sodium excreted was approximately doubled. Moreover, in individual patients, in the transition from 3.5 to the $7.0 \mathrm{~g}$ salt intake, the lower the GFR, the larger was the change in fractional sodium excretion. Similar data have recently been reported by Kleeman, Okun, and Heller (5).

The fact that fluctuations in sodium excretion/ nephron must be very large at low GFR opens the possibility for differentiating between the contribution of tubular vs. glomerular factors in the modulation of sodium excretion in man. The basis for this statement is as follows: An increase in daily salt intake of $3.5 \mathrm{~g}$ requires an increase in sodium excretion of approximately $60 \mathrm{mEq} /$ day or an average of $41 \mu \mathrm{Eq} / \mathrm{min}$. At a GFR of 120 $\mathrm{ml} / \mathrm{min}$, a change in GFR of only $1 \%$ would increase the delivery of sodium to the tubules by about four times this amount; it therefore is virtually impossible to distinguish a subtle change in GFR from an alteration in tubular reabsorption under these conditions. In contrast, at a GFR of $4 \mathrm{ml} / \mathrm{min}$, a $1 \%$ change would increase the filtered load by less than $6 \mu \mathrm{Eq} / \mathrm{min}$; thus, if GFR changes determined the increased excretion, a much larger fractional change in GFR would be required. On the other hand, if tubular changes were responsible, the change in fractional excretion of sodium would be about 16 times as great, at a GFR of 4 , as at a GFR of 120 . With larger saline loads, the exaggerated swings in excretion/nephron required of the diseased kidney might enhance the ability to discriminate between tubular and glomerular factors.

The results of ECF volume expansion in patients with low filtration rates (Table I) suggest that changes in fractional sodium reabsorption, rather than GFR, played the key role in modulating excretion. In six of the nine studies, the changes in sodium excretion could not be accounted for quantitatively by concomitant changes in GFR ; indeed, in three patients GFR decreased. Even in the three studies, in which filtered sodium increased more than sodium excretion, the increment in excretion ranged from 50 to $68 \%$ of the simultaneous increment in the filtered load. Thus, less than half of the increment in filtered sodium was reabsorbed. The composite data thus imply that hyperfiltration is not the major determinant of the decrease in fractional sodium reabsorption. However, to examine this question experimentally, the studies with PTH were performed (Table II). The results indicate that when GFR was increased without concomitant expansion of ECF volume, the increment in sodium excretion rate averaged only $19 \%$ of the increment in filtered sodium ${ }^{1}$; thus an average of $81 \%$ of the increased filtered load of sodium was reabsorbed. The changes in fractional sodium reabsorption in these patients generally were small, and in 6 of the 18 studies fractional reabsorption increased. These findings are in marked contrast to those observed in the patients subjected to ECF volume expansion. The study presented in Table III is of interest in terms of the differential effects between saline loading and hyperfiltration. In consequence of ECF volume expansion, GFR increased by $8.7 \%$, whereas fractional sodium reabsorption decreased from 72.5 to $62.9 \%$. ECF expansion was then maintained and an increase in GFR was superimposed by the infusion of PTH. GFR increased by an additional $22.2 \%$; yet fractional sodium reabsorption stayed almost constant, decreasing from the previous level of $62.9 \%$ to an average of $61.4 \%$. Thus net sodium reabsorption increased with the PTH-induced increment in GFR (and filtered load) despite the presence of volume expansion; but glomerulo-tubular balance for sodium remained essentially constant. The dissociation between the effects of a primary increase in GFR and an increase attendant upon saline loading is also depicted in Fig. 4. ECF expansion and PTH infusion were performed on separate days. Hyperfiltration was greater with PTH infusion; yet the latter produced relatively little effect on sodium excretion, whereas ECF expansion initiated a substantial reduction in fractional sodium reabsorption. Two other patients were studied during both volume expansion and $\mathrm{PTH}$ infusion and the results are included in Tables I and II. ${ }^{2}$

We believe that the foregoing data are consistent with the view that a factor (or factors)

\footnotetext{
1 These results are similar to those recently reported by Lindheimer, Lalone, and Levinsky in dogs in which GFR was increased without expanding ECF volume (6).

2 Data from three patients in whom both studies were performed are designated as Experiments 3, 4, and 6 in Table I, and as Patients 3,7 , and 8 in Table II.
} 
other than changes in filtration rate and mineralocorticoid hormone activity participated in the modulation of sodium excretion in the uremic patients. Phenomenologically, the change in fractional sodium reabsorption after ECF volume expansion has the same charactertistics as those observed in normal animals receiving saline infusions (7) where at least one of the determining events presumably is a hormone (8). The sustained increase in sodium excretion rate/nephron observed in dogs subjected to a marked reduction in nephron population also appears to be mediated by the same factor(s) (9). Theoretically the changes in fractional sodium reabsorption associated with volume expansion in the present patients could be mediated by an increase in activity of a natriuretic hormone; alternatively it could relate to hemodynamic changes within the kidney (10). Finally, a combination of both events could be responsible. Although intuitively we would favor the change in activity of a hormone as being the most likely modulator, further observations are necessary to determine the relative importance of the various possible contributing factors.

\section{ACKNOWLEDGMENT}

This study was supported by U. S. Public Health Service Research grants AM-09976 and FR-36, General Clinical Research Centers Branch, Division of Research Facilities and Resources.

\section{REFERENCES}

1. Fitzhugh, F. W., Jr., R. L. McWhorter, Jr., E. H. Estes, Jr., J. V. Warren, and A. J. Merrill. 1953. The effect of application of tourniquets to the legs on cardiac output and renal function in normal human subjects. J. Clin. Invest. 32 : 1163.

2. Rieselbach, R. E., S. W. Shankel, E. Slatopolsky, H. Lubowitz, and N. S. Bricker. 1967. Glucose titration studies in patients with chronic progressive renal disease. J. Clin. Invest. 46: 157.

3. Lubowitz, H., E. Slatopolsky, S. Shankel, R. E. Rieselbach, and N. S. Bricker. 1967. Glomerular filtration rate-determination in patients with chronic renal disease. J. Am. Med. Assoc. 199: 252.

4. Roe, J. H., J. H. Epstein, and N. P. Goldstein. 1949. A photometric method for the determination of inulin in plasma. J. Biol. Chem. 178: 839.

5. Kleeman, C. R., R. Okun, and R. J. Heller. 1966. The renal regulation of sodium and potassium in patients with chronic renal failure and the effect of diuretics on the excretion of these ions. Ann. N.Y.Acad. Sci. 139: 520 .

6. Lindheimer, M. D., R. C. Lalone, and N. G. Levinsky. 1967. Evidence that an acute increase in glomerular filtration has little effect on sodium excretion in the dog unless extracellular volume is expanded. J. Clin. Invest. 46: 256.

7. DeWardener, H. E., I. H. Mills, W. F. Clapham, and C. J. Hayter. 1961. Studies on the efferent mechanism of the sodium diuresis which follows the administration of intravenous saline in the dog. Clin. Sci. 21: 249.

8. Martinez-Maldonado, M., N. A. Kurtzman, F. C. Rector, Jr., and D. W. Seldin. 1967. Evidence for a hormonal inhibitor of proximal tubular reabsorption. J. Clin. Invest. 46: 1091.

9. Schultze, R. G., E. Slatopolsky, B. Tall, W. Walker, M. Levy, and N. S. Bricker. 1966. The regulation of sodium excretion in uremia: a new dimension in the characterization of "third factor." Trans. Assoc. Am. Physicians. 79: 322.

10. Earley, L. E., and R. M. Friedler. 1965. Changes in renal blood flow and possibly the intrarenal distribution of blood during the natriuresis accompanying saline loading in the dog. J. Clin. Invest. 44: 929. 